\title{
Carney-Stratakis syndrome
}

INSERM

\section{Source}

INSERM. (1999). Orphanet: an online rare disease and orphan drug data base. CarneyStratakis syndrome. ORPHA:97286

Carney-Stratakis syndrome is a recently described familial syndrome characterized by gastrointestinal stromal tumors (GIST) and parag ang liomas, often at multiple sites. 